\title{
Parents seeking help after cot death. How atypical is their experience?
}

\author{
NICOLA J CRICHTON, S R LIMERICK, AND R G CARPENTER \\ From the London School of Hygiene and Tropical Medicine, London WC1E 3HT, UK
}

SUMmARY A survey of 241 cases of cot death reported to the Foundation for the Study of Infant Deaths is compared with more formal epidemiological studies. As expected the cases tend to be drawn from the higher social classes, and this selection affects some of the data-for instance, mothers' age and feeding practice. Nevertheless, data relating to the infants and their histories are remarkably similar to data from other studies. The survey provides a continuous epidemiological monitor as well as being of therapeutic value to the parents and should be continued.

Cot death-that is, unexpected infant death without obvious clinical or pathological cause-is the third largest group of infant deaths. In contrast to other forms of mortality these deaths are most frequent in the second month of life, ${ }^{1}$ and at an international symposium held in Cambridge in 1970 Wedgwood underlined the devastating effect of those deaths on the parents. ${ }^{2}$ After that conference a charitable organisation, The Foundation for the Study of Infant Deaths, was set up whose aims include the support of bereaved parents.

The foundation has produced an "information to parents" leaflet that has been distributed to all coroners, consultant paediatricians, most general practitioners, and many health visitors with the intention that it should be given to parents bereaved in this way. The leaflet concludes by inviting the parents to contact the foundation for further help and information. As a result the foundation are contacted by an ever increasing number of parents. In 1981 the total exceeded 500 , which is more than $25 \%$ of all unexpected infant deaths in England and Wales.

Since 1977 most parents who have contacted the foundation have been invited to complete two questionnaires. The first provides general epidemiological data and the second gives information on how the death was managed and the support the family received.

The foundation is a major sponsor of cot death related research and has supported over 40 projects in which over $£ 0.5 \mathrm{~m}$ has been allocated. The foundation's view of the problem is inevitably influenced by the experience of parents who contact them for help and who by their donations make a substantial contribution to the funds for research These parents are, however, self selected, and it is important to have information as to the biases $\mathbb{\mathbb { D }}$ 음 introduced by selection. The purpose of this study is, $\stackrel{\leftrightarrow}{\mathbb{1}}$ therefore, to compare the characteristics and $\varrho$ histories reported by parents contacting the $\mathbb{O}^{\circ}$ foundation with those of parents interviewed in a general epidemiological survey.

\section{Material}

The questionnaire used for this survey was a general epidemiological questionnaire that had been developed for the Inner North London Survey ${ }^{3}$ and covers the circumstances of death, the clinical history of the child's development, with special reference to the last three weeks before death, and details of the family and their recent health.

To be included in this study parents must have heard of the foundation, be motivated enough to contact the foundation, and have completed the questionnaire. Often there was considerable delay between the child's death and completion of the questionnaire. To help ensure accurate information only questionnaires completed within 12 weeks of the death were included in the analysis. Cases in which the child is reported as having a malformation or other obvious cause of death were eliminated as were infants that died under the age of 1 week.

Included in this study are 241 cases whose death occurred between May 1977 and May 1980, representing about $50 \%$ of questionnaires completed during this period.

The most comparable recent epidemiological 
study is the Inner North London Survey which included 308 cases of unexpected infant death that occurred between March 1975 and September 1979 in nine areas in the south of England. The findings of the "nine area study" are reported in a series of four papers. ${ }^{4-7}$ Findings from this study will be referred to as the nine area study without further reference.

\section{Findings}

\section{GENERAL CHARACTERISTICS}

\section{Children}

The ratio of boys to girls in the present series is 1.30 to 1 . This is very close to the sex ratio previously reported by Carpenter, ${ }^{8}$ is slightly lower than that reported for England and Wales, ${ }^{1}$ and not significantly different from that found in the nine area study (1.70 to 1$)$ in which the proportion of male deaths was exceptionally high.

The age distribution of the cases is typical of that found in other studies with the peak incidence occurring between 2 and 3 months. Twenty three per cent of the cases were aged betweer 8 and 12 weeks while only $12 \%$ were more than 24 weeks.

In common with all previous studies most of the cases died in the winter months; very few children died in June, July, or August. The seasonal variation observed in this study is similar to that found in the nine area study (table 1) and cannot be accounted for by seasonal variation in the number of births. The data are too small to examine variations of peak incidence with the month of birth or of sex ratio with age, such as described by Carpenter et al. ${ }^{1}$

Table 1 Seasonal distribution of deaths in the two surveys

\begin{tabular}{llc}
\hline & \multicolumn{2}{l}{ \% of cases in study } \\
\cline { 2 - 3 } & $F^{*}$ & NAS† \\
\hline Month of death: & & \\
January-March & 45 & 37 \\
April-June & 19 & 24 \\
July-September & 9 & 11 \\
October-December & 28 & 27 \\
Total & 100 & 100 \\
\hline
\end{tabular}

-Present study-241 cases.

†Nine area study-308 cases.

Most children (45\%) were found ill or dead between 0600 and 1200 as in other studies. Of the cases found dead in the morning, $37 \%$ had been seen within three hours of death but most were found when the parents awoke. Twenty two per cent of the 241 infants had not been seen for six or more hours, nine had not been looked at for more than 12 hours, and one of those children had not been seen for 15 hours.
Three of the infants died while being nursed or fed. The remainder died in their bed (where bed means cot, pram, or carrycot). Of these children, $91 \%$ were found on their stomach, and this was recorded as the normal position for $94 \%$ of the cases found lying in this way. Analysis of the sort of bedding and position of the covers is in line with previous studies and provides no evidence to support the idea that suffocation is a possible factor in more than a handful of cases.

Six per cent of the cases were less than $2500 \mathrm{~g}$ at birth. This is a significantly smaller proportion of low birthweight cases than was found in the nine area study, $\mathrm{p}<0.01$, and is similar to the proportion among all live births. Only seven of the births were recorded as illegitimate, a significantly lower number than that found in other studies. Eighty five per cent of the cases are recorded as having been taken to a clinic, a much larger percentage than found in other studies.

\section{Parents}

Only five of the infants had a mother whose age was 20 or under, the youngest mother being 19 . Forty five per cent of the mothers were between 25 and 30 , (mean 28.2). This is 3.8 years older than the mean mothers' age in the nine area study. Only $23 \%$ of the mothers are primiparous compared with $28 \%$ in the nine area study. The slight difference in parity does not, however, explain the differences between the age of mothers in the two studies.

Difficulties arose in establishing social class for many of the cases in this study because of the vagueness of the response to the question on father's occupation. In table 2 the classification of cases in three groups is compared with 1971 census data for England and Wales. Cases in the study clearly tend to be drawn from the higher social classes although some members of classes IV and V are included. The parents in the present study are on average more than half a class higher than the parents in the nine area study.

\section{BREAST FEEDING}

For $70 \%$ of the cases, initial feeding is recorded as completely breast fed and, for a further $10 \%$,

Table 2 Comparison of social class for families of cases with that for married women aged under 40 in England and Wales

\begin{tabular}{lllll}
\hline \multicolumn{5}{l}{$\%$ in social classes } \\
\cline { 2 - 5 } & I and II & III & IV and $V$ & All classes \\
\hline Cases & 50 & 40 & 10 & 100 \\
England and Wales & 21 & 45 & 34 & 100 \\
\hline
\end{tabular}


partially breast fed. Thus $80 \%$ of cases included breast feeding in their initial diet which is significantly $(\mathrm{p}<0.01)$ higher than the number recorded as partially or completely breast fed initially in the nine area study (table 3 ). When a comparison is made with the percentage of infants initially breast fed in England and Wales by social class, year, and parity, ${ }^{9}$ the proportion of cases in this study that were initially breast fed seems appropriate to the social group represented and the period of the study.

Bottle feeding has been associated with unexpected infant death in several studies, including the nine area study. We have therefore compared the age distribution of totally breast fed infants in this study with that of infants partially or completely bottle fed, using life table methods as follows:

Two groups were considered: (1) cases completely breast fed and (2) cases with something other than breast milk in their diet. Initally group 1 contained 168 children and group 2 the rest. Children in group 1 were censored from that group when "other" food was introduced and then transferred to group 2. It is assumed that for the week of transfer half the period was spent in each group. The results are presented in the figure, which shows that between the ages of 4 and 12 weeks a greater proportion of breast fed infants had died than group 2 infants. The differences are however small and not statistically significant. The graph cannot be meaningfully extended beyond 16 weeks.

Coombs has suggested that in some unexpected infant deaths an anaphylactic reaction may have occurred when a sensitive infant aspirates cows' milk. ${ }^{10}$ If this were so one might expect infants who have been almost exclusively breast fed to be at greatest risk when cows' milk is first introduced. This was investigated by looking at how soon the children died after transfer from group 1 to group 2 allowing for age at that time. The number "dying early" was calculated, with "early" taken as less than two weeks after transfer, and this number was compared with expected deaths based on a combined life table for all infants. Some 20 early deaths occurred and 16 were expected. This slight excess of early deaths is therefore not statistically significant.

Table 3 Comparison of initial feeding of cases in present study with the nine area study

\begin{tabular}{llll}
\hline & \multicolumn{2}{l}{ Initial feeding (\%) } & \\
\cline { 2 - 4 } & $\begin{array}{l}\text { Wholly or partially } \\
\text { breast fed }\end{array}$ & $\begin{array}{l}\text { Not breast } \\
\text { fed }\end{array}$ & Total \\
\hline Present study & 80.1 & 19.9 & 100 \\
Nine area study & 52.9 & 47.1 & 100 \\
\hline
\end{tabular}

\section{SYMPTOMS AND VISITS TO DOCTOR}

The questionnaire asks for details of symptoms in the child and family that occurred in the last three weeks, details of visits to the family doctor or child health clinic, and the dates of those events. Since several weeks had almost invariably elapsed before the forms were completed, little information on the dates of events was recorded. Four infants were excluded from the analysis of symptom data due to absence of information.

Of the remaining 237 infants, $78 \%$ had one or more symptoms at some time during their last three weeks. In the nine area study $85 \%$ of cases had one or more symptoms at some time in the last three weeks; although the percentages are essentially similar, the difference between the percentage of cases with symptoms in the two studies is just statistically significant $(0.01<\mathrm{p}<0.05)$.

In $86 \%$ of cases there was a history of symptoms in either the child or other members of the household in the three weeks before death compared with $90 \%$ in the nine area study.

Seventy per cent of infants with symptoms had respiratory symptoms and as might be expected there was a statistically highly significant association between respiratory symptoms in the child and a history of respiratory symptoms in other members of the household $(p<0.001)$.

Table 4 shows the percentage of infants seeing a doctor for illness or other reasons-for instance, routine check up by the number of symptoms the infant had in the last three weeks. The table shows that about $24 \%$ of infants saw a doctor routinely in

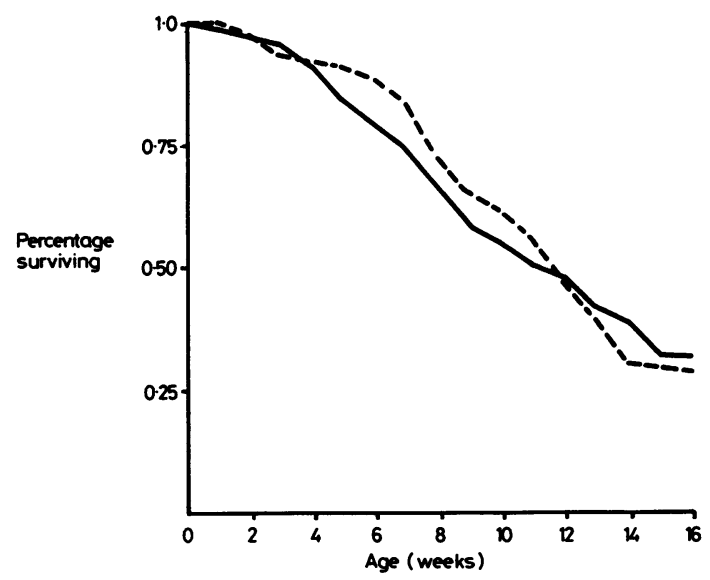

Survival curve for fully breast fed and bottle fed infants. Breast fed, - - bottle fed. 
Table 4 Visits to doctor by reason and number of symptoms in the last three weeks

\begin{tabular}{|c|c|c|c|c|c|c|}
\hline \multirow{3}{*}{$\begin{array}{l}\text { No of } \\
\text { symptoms }\end{array}$} & \multicolumn{4}{|c|}{ \% Seeing doctor } & & \\
\hline & \multirow{2}{*}{$\begin{array}{l}\text { Not } \\
\text { seen }\end{array}$} & \multirow{2}{*}{$\begin{array}{l}\text { For } \\
\text { illness }\end{array}$} & \multirow{2}{*}{$\begin{array}{l}\text { Other } \\
\text { reasons }\end{array}$} & \multirow[b]{2}{*}{ Total } & \multicolumn{2}{|c|}{$\begin{array}{l}\text { Cases with } \\
\text { symptoms }\end{array}$} \\
\hline & & & & & No & $\%$ \\
\hline 0 & 79 & 0 & 21 & 100 & 53 & 22 \\
\hline 1 & 51 & 24 & 25 & 100 & 91 & 39 \\
\hline 2 & 50 & 25 & 25 & 100 & 64 & 27 \\
\hline$>3$ & 45 & 34 & 21 & 100 & 29 & 12 \\
\hline \multirow{2}{*}{\multicolumn{3}{|c|}{$\begin{array}{l}\text { Total } \\
\text { No information }\end{array}$}} & & & 237 & 100 \\
\hline & & & & & 4 & \\
\hline
\end{tabular}

the last three weeks irrespective of whether they had symptoms or not. In addition between $24 \%$ and $34 \%$ of infants with symptoms were taken to the doctor but even when there was a history of three or more symptoms $45 \%$ of infants did not see a doctor. These figures are remarkably similar to those of the nine area study in which only $50 \%$ of the cases with a history of symptoms were seen by a doctor.

\section{Discussion}

The study shows that the case histories reported to the foundation are similar to those of the nine area study in respect of age, sex, season, time of day, sleeping position, and type of bedding. Not surprisingly the social class of those self selected parents is above average but despite this selection $10 \%$ are in social classes IV or V. The age distribution of these mothers reflects the social class selection. The proportion of breast fed infants appears no higher than is to be expected from the social class distribution of the parents. This may also explain the small proportion of low birthweight infants. The comparatively small proportion of illegitimate infants is hardly surprising in a self administered questionnaire.

The proportion of infants with symptoms is similar to that found in other studies and is in agreement with the impression of other workers that many of these infants are not entirely well at the time of death. ${ }^{11}{ }^{12}$ Nevertheless, as other studies have found, only about half have been seen recently by a doctor. Analysis shows, however, that, as in the nine area study, a substantial proportion of the symptoms are behavioural changes such as restlessness or sleepiness rather than overt symptoms of illness. This may have led to underestimation of the importance of the symptom and uncertainty as to whether to contact the doctor. The foundation has produced a green card to provide appropriate guidance and similar information is now being given by several health authorities in their baby books. Such advice may help to prevent some unexpected deaths in the long run.

Several studies have indicated that breast feeding may be prophylactic. The effect could be direct by preventing infection or an anaphylactic reaction or indirect through improved bonding and increased awareness of the infant's needs and health. The present study includes 73 infants under the age of 16 weeks who were reported to be totally breast fed, $30 \%$ of all the deaths. Life table analysis does not suggest that the age distribution of these deaths is any different from that of the remainder. There is some suggestion that breast fed infants are at increased risk at the time cows' milk is introduced to their diet but this requires confirmation in other studies.

Three of the infants were reported to have collapsed and died while being being nursed. If those episodes are typical of terminal events in cot death rather than the near miss episode it could be that apnoea alarms would serve as death monitors rather than as means of preventing death.

The questionnaire had several sections for parents to expand on their answers and a final section for free comments such as "nothing was done until now to make me think anything was being done to avoid these baby deaths" and "I feel by filling in this I am helping doctors knowledge to help other babies" are typical.

\section{Conclusions}

As expected the families represented in the sample of respondents to the foundation tend to be drawn from higher social classes but classes IV and V are by no means totally unrepresented. This selection affects some of the data - for example, age of mother and feeding practice. Data relating to the infants and their histories are in remarkable agreement with data from the nine area study. The parents contacting the foundation form a large readily accessible source of epidemiological data relating to unexpected infant death which may be valuable for answering certain questions. Thus after allowing for the social class bias a survey of this type can provide a general continuing epidemiological monitor. At the same time the questionnaires appear to be of therapeutic value to the parents. It therefore seems worth while for the study to continue.

\section{References}

${ }^{1}$ Carpenter RG, Gardner A. Variations in unexpected infant death rates relating to age, sex and season. In: Studies in sudden infant deaths. (Studies on medical and population subjects, No 45.) London: HMSO, 1982: 23-31. (OPCS report.)

${ }^{2}$ Wedgwood RJ. In: Camps FE, Carpenter RG, eds. Sudden and unexpected death in infancy (cot death). Bristol: Wright, 1972: 22-8 
${ }^{3}$ Watson E. A two year study of sudden death in infancy in inner north London. Public Health London 1975; 89: 153-5.

4 Watson E, Gardner A, Carpenter RG. An epidemiological and sociological study of unexpected death in infancy in nine areas of southern England. I. Epidemiology. Med Sci Law 1982; 21: 78-88.

${ }^{5}$ Watson E, Gardner A, Carpenter RG. An epidemiological and sociological study of unexpected death in infancy in nine areas of southern England. II: Symptoms and patterns of care. Med Sci Law 1982; 21: 89-98.

${ }^{6}$ Watson E. An epidemiological and sociological study of unexpected death in infancy in nine areas of southern England. III. Bereavement. Med Sci Law 1982; 21: 99-104.

${ }^{7}$ Carpenter RG, Gardner A, Watson E. An epidemiological and sociological study of unexpected death in infancy in nine areas of southern England. IV: Evaluation of scoring. Med Sci Law 1982; 21: 105-11.
${ }^{8}$ Carpenter RG. In: Camps FE, Carpenter RG, eds. Sudden and unexpected death in infancy (cot death). Bristol: Wright, 1972: 7-15

${ }^{9}$ Martin J, Monk J. Infant feeding 1980 London: Office of Population Consensus and Surveys, 1982.

${ }^{10}$ Anderson KJ, McLaughlan P, Devey M, Coombs RRA. Anaphylactic sensitivity of guinea-pigs drinking different preparations of cow's milk and infant formulae. Clin Exp Immunol 1979; 35: 454-61.

${ }^{11}$ Carpenter RG, Gardner A, Pursall E, McWeeny PM, Emery JL. Identification of some infants at immediate risk of dying unexpectedly and justifying intensive study. Lancet 1979; iii: 343-6.

${ }^{12}$ Cameron MJ, Watson E. Sudden death in infancy in inner north London J Pathol 1974; 117: 55-61.

${ }^{13}$ Office of Population and Census Surveys. 1971 Fertility tables for England and Wales. London: HMSO, 1979. 